\title{
Prevalence and Risk Factors for Musculoskeletal Pain and Coping Strategies in School Teachers
}

\author{
Saravanan Murugan ${ }^{1 *}$, Prerana Saravanan², Disha Avaiya², Ibrahim Bawa², \\ Shah Charmi ${ }^{2}$ and Vaghasiya Ekta ${ }^{2}$ \\ 'Shree Bharatimaiya College of Optometry and Physiotherapy, Veer Narmad South Gujarat University, \\ Surat - 395007, Gujarat, India; saravananmurugan77@gmail.com \\ ${ }^{2}$ Sarvajanik College of Physiotherapy, Veer Narmad South Gujarat University, Surat - 395003, Gujarat, India
}

\begin{abstract}
Introduction: School teachers have high prevalence of work related musculoskeletal disorders which decrease productivity at work due to sick leave and absenteeism. In India, more traditional methods of teaching are used as compared to other countries, and this difference encouraged us to determine prevalence of musculoskeletal pain, risk factors and coping strategies adopted by teachers. Methods: A self-administered Questionnaire was distributed to 810 particcipants. 567 responses were received out of which 30 questionnaires were incomplete. The self-administered Questionnaire included 31 questions under 5 categories: General Profile, Occupational profile, Health/Musculoskeletal pain profile, Perceived risk factors and Coping Strategies. Descriptive statistics of mean and standard deviation, frequency were calculated for continuous and categorical variables respectively. Binary logistic regression analysis was performed to determine the association of musculoskeletal symptoms with demograpic factors and working conditions. Results: 112 (20.9\%) reported having musculoskeletal pain. Low back (48.2\%) was commonly affected. 50.9\% had chronic pain and $71.4 \%$ reported pain interfered with occupational routine. $48.2 \%$ reported with sleep disturbances. Commonly percieved factor was standing for prolonged periods (76.8\%). Risk factor analysis using logistic regression model on cause of pain showed statistical significance $\left(\chi^{2}(27)=77.169, p<0.005\right)$. Females were 3.952 times more likely to exhibit pain than males (OR 3.952, 95\% CI 1.6949.217). Commonly reported coping strategy was visiting a Physiotherapist (44.6\%). While $33 \%$ coped up with pain using prescribed analgesics, none of them opted to rest. Despite high prevalence and severity, only $17 \%$ had frequented absenteism to work by taking sick leave. Discussion: Prevalence rate of musculoskeletal pain was found to be higher among school teachers as per the results of this present study. Prevalence and risk factor perceptions of school teachers as reported in this study can be of significance in understanding and addressing these factors and appropriate measures to prevent and overcome them can be devised based on these results. Since the risk factors for musculoskeletal symptoms can be multifactorial in nature, the results of this present study need to be correlated with all possible mechanisms related to this population and further studies to determine the effectiveness of appropriate ergonomic modifications should be taken into consideration.
\end{abstract}

Keywords: Activities of Daily Living, Coping Strategies, Risk Factors, Teachers, Work Related Musculoskeletal Disorders

\section{Introduction}

Work-related Musculoskeletal Disorders (WMSDs) is defined as injuries or disorders of the musculoskeletal system, which includes muscles, nerves, tendons, joints, cartilages and spinal discs that may be associated with exposure to risk factors in the workplace. The World Health Organization (WHO) has described the multifactorial risk factors was responsible for WMSDs among workers. Physical demands that are imposed on the body at the work place such as awkward or fixed posture for a long time, heavy lifting, and repetitive tasks are reported to be the causes or aggravating factors for $\mathrm{WMSD}^{1}$.
Musculoskeletal disorders represent one of the most common and most costly occupational health problems in both developed and developing countries. With social production highly mechanized, WMSDs are becoming a major health problem encountered by professionals. The prevalence of WMSDs linearly correlates with age and length of service. Because of the different work characteristics, conditions and working strength, multiple parts of WMSDs are also different.

Concerns about the risk of WMSDs have been increasing in the education world. School teachers in general, relative to other occupational groups, have a high prevalence of WMSDs. WMSDs decrease productivity at work due to sick leave,

*Author for correspondence 
absenteeism and early retirement. Musculoskeletal complaints, especially of the lower back, neck, shoulders, are also common among teachers due to prolonged desk work, prolonged standing in class and repetitive overhead writing on the board, prolonged sitting resulting from frequent reading, preparation of lessons and marking of assignments and working on computer ${ }^{2}$. Several socio-demographic, psychological, physical and organizational factors are related to triggering, developing, and maintaining musculoskeletal pain.

Detailed review of literature by the researchers from various databases revealed scanty literature on WMSDs in this occupation ${ }^{3-9}$. The methods of teaching, materials and tools used in teaching methodology, number of working hours and working patterns vary from country to country. In India, there are more traditional methods of teaching as compared to other countries, and this difference encouraged the researchers to conduct this study to determine the prevalence of musculoskeletal pain among school teachers in India.

Since there is an increasing number of educational institutions mushrooming in the country, and an equally increasing number of teachers, results of this study would be of high significance not only in understanding the prevalence of musculoskeletal pain but also will pave way to understand the common factors that possibly might be contributing to the symptoms. Since, it also aims to determine the coping strategies commonly employed by the teachers to overcome this musculoskeletal pain it will also provide insight into preventing the musculoskeletal pain in teachers.

\section{Methodology}

This cross sectional study was conducted to determine the prevalence of musculoskeletal pain among school teachers. Prior to commencement of the study, a written permission letter to conduct the study in the respective schools were given to the Principals of 27 schools. Principals from 7 schools refused to provide permission for the study for no obvious reasons. At the end, 20 schools were included for collecting data from the teachers. Informed consent was obtained from the participants before the commencement of the study by explaining the details of the study in accordance with the institutional ethical standards of the ethics committee on human experimentation and the Helsinki declaration of 1975. Self-administered questionnaires were distributed to 810 school teachers from these 20 private schools which included instructions for filling and teachers were informed to return it within a week. Filled in questionnaires were collected after a gap of one week. Questionnaires were checked for completeness once received from the teachers. Incomplete questionnaires were not taken for data analysis. Out of the 810 questionnaires distributed, 567 were received back from the teachers, out of which 30 questionnaires were incomplete.

The self-administered Questionnaire included 31 questions under 5 categories: General Profile, Occupational profile, Health/Musculoskeletal pain profile, Perceived risk factors and Coping Strategies. Occupational details like years of expereince as a teacher, school timings, working hours in a day, number of students handling, age group of students, availability of break time were included. Musculoskeletal profile included presence of pain perceived by the participants. Instructions were provided to participants to mention pain perceived only due to their work and not to any recent or past trauma. Severity of pain and body parts invovled were also included. Pain pattern and interference of pain in work and daily routine were also recorded. Common factors related to their work as teachers in a school environment which potentially was perceived by them as a reason for their pain related to work, were included as a part of the questionnaire. Finally, common coping mechanisms or strategies used by the participants to overcome their pain were recorded. All the questions were close ended with appropriate options as responses, relevant to the question. Some questions for example, part of the body affected with pain, had multiple responses.

Descriptive statistics of mean and standard deviation, frequency were calculated for continuous and categorical variables respectively. Binary logistic regression analysis was performed to determine the association of musculoskeletal symptoms with demographic factors and working conditions. Level of significance was set at $\mathrm{p} \leq 0.05$ for all the analyzed data. All statistical analyses were performed using SPSS v 20.0.

\section{Results and Analysis}

The mean and frequency values of physical, demographic characteristics and working conditions of participants like age, gender, working experience, school timing, working hours, and number of students handled per class and break time provided are represented in (Table 1).

$84.7 \%$ of the participants were female teachers and only $11.4 \%$ of the participants were freshers with less than 1 years of experience. $69.1 \%$ of them worked for an average of 6-7 hours a day with $58.8 \%$ of teachers getting less than 2 hours of break time from their work routine. While $39.3 \%$ of teachers in this study handled more than 50 students in a class, $55.3 \%$ handled a range of 26 to 50 students.

112 out of 537 participants in this study had musculoskeletal symptoms. Prevalence of musculoskeletal symptoms in this study population was found to be $20.9 \%$.

Anatomical sites of the body most commonly affected due to work as reported by the participants are represented in (Figure 1). 
Table 1. Demographic characteristics of participants

\begin{tabular}{|c|c|}
\hline Variables & Mean (SD), $\mathrm{n}=537$ \\
\hline Age (in Years) & $33.16(8.80)$ \\
\hline Variables & n (\%), (n=537) \\
\hline \multicolumn{2}{|c|}{ Gender } \\
\hline Male & $82(15.3)$ \\
\hline Female & $455(84.7)$ \\
\hline \multicolumn{2}{|c|}{ Experience (in years) } \\
\hline$<1$ & $61(11.4)$ \\
\hline $1-5$ & $177(33.0)$ \\
\hline $6-10$ & $143(26.6)$ \\
\hline$>10$ & $156(29.1)$ \\
\hline \multicolumn{2}{|c|}{ School Timimg } \\
\hline Morning & $404(75.2)$ \\
\hline Afternoon & $113(21.0)$ \\
\hline Full Time & $20(3.7)$ \\
\hline \multicolumn{2}{|c|}{ Working Hours per day } \\
\hline$<3$ & $8(1.5)$ \\
\hline $3-5$ & $102(19.0)$ \\
\hline $6-7$ & $371(69.1)$ \\
\hline$>7$ & $56(10.4)$ \\
\hline \multicolumn{2}{|c|}{ Break Time provided (in Hours) } \\
\hline No Break & $187(34.8)$ \\
\hline$<2$ & $316(58.8)$ \\
\hline$>3$ & $34(6.3)$ \\
\hline \multicolumn{2}{|c|}{ Number of students handled per class } \\
\hline$<25$ & $26(4.8)$ \\
\hline $26-50$ & $297(55.3)$ \\
\hline $51-75$ & $211(39.3)$ \\
\hline $76-100$ & $2(0.4)$ \\
\hline$>100$ & $1(0.2)$ \\
\hline
\end{tabular}

Low back was found to be the most commonly affected body site $(48.2 \%)$, followed by Shoulder (40.2\%) and knee $(38.4 \%)$.

Frequency distribution of duration, pattern and severity of musculoskeletal symptoms in participants are represented in (Table 2).

$77.7 \%$ of participants with musculoskeletal symptoms complained of the symptoms present during their occupation and the rest had it throughout. Moderate severity was reported by $56.3 \%$ of participants (Table 2 ).

Table 3 represents the frequency of interference of musculoskeletal symptoms in Activities of daily living of participants.

It was found that $58 \%$ of participants had difficulty in performing Activities of Daily Living (ADLs) due to the presence of symptoms. Getting up from floor was found to be

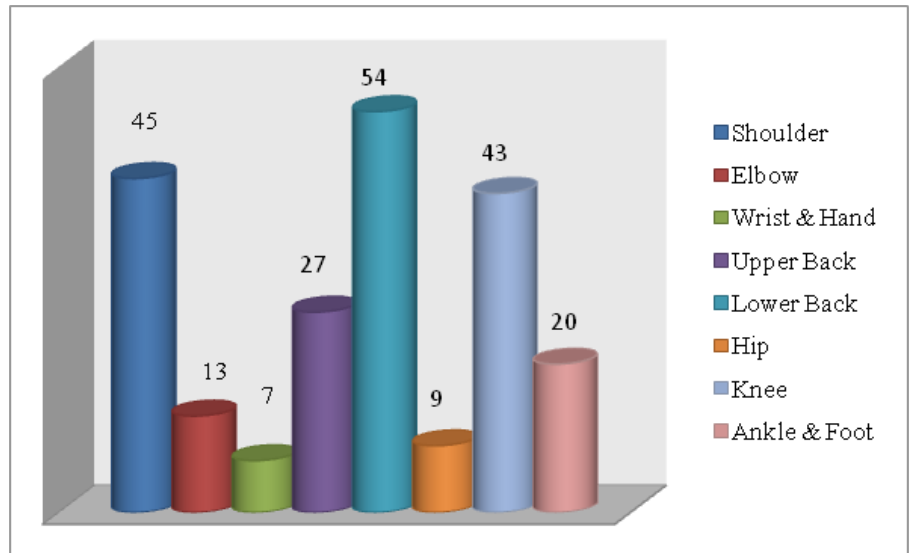

Figure 1. Region wise distribution of musculoskeletal symptoms in participants.

Table 2. Duration, Pattern and severity of musculoskeletal symptoms in participants

\begin{tabular}{|c|c|}
\hline Variables & $\mathrm{n}(\%),(\mathrm{n}=112)$ \\
\hline \multicolumn{2}{|c|}{ Duration } \\
\hline$<3$ months & $28(25.0)$ \\
\hline 4-6 months & $13(11.6)$ \\
\hline 7-12 months & $14(12.5)$ \\
\hline$>12$ months & $57(50.9)$ \\
\hline \multicolumn{2}{|c|}{ Pattern } \\
\hline Continous & $25(22.3)$ \\
\hline During Work & $87(77.7)$ \\
\hline \multicolumn{2}{|c|}{ Severity } \\
\hline Mild & $41(36.6)$ \\
\hline Moderate & $63(56.3)$ \\
\hline Severe & $8(7.1)$ \\
\hline
\end{tabular}

Table 3. Interference of symptoms with Activities of Daily Living (ADL)

\begin{tabular}{|l|c|}
\hline ADL & $\mathbf{n ~ ( \% ) , ( \mathbf { n } = 1 1 2 )}$ \\
\hline Overall & $65(58.0)$ \\
\hline Getting up from Bed & $25(22.3)$ \\
\hline Getting up from floor & $37(33.0)$ \\
\hline Grooming & $4(3.6)$ \\
\hline Driving & $11(9.8)$ \\
\hline Cooking & $9(8.0)$ \\
\hline Toileting & $5(4.5)$ \\
\hline Bending activities & $15(13.4)$ \\
\hline Stair Climbing & $33(29.5)$ \\
\hline
\end{tabular}

the most difficult activity due to the symptoms (33\%), followed by climbing up and down stairs (29.5\%) (Table 3 ).

Table 4 represents the frequency of musculoskeletal symptoms interfering in working abilities of participants in their work place. 
Interference in occupation was found to be higher (71.4\%) as compared to ADLs and standing for long duration (52.7\%) was reported as the most difficult activity (Table 4).

$48 \%$ of participants reported that their musculoskeletal symptoms interfered with their sleep pattern and despite the presence and severity of symptoms, only $17 \%$ of teachers have opted to take frequent sick leaves.

Table 5 represents the self reported, commonly perceived risk factors related to teaching profession as reported by the participants.

When questioned on the commonly perceived risk factors considered to be responsible for their musculoskeletal symptoms, teachers reported standing for long periods of time (76.8\%) as the most common cause followed by stair climbing and evaluating answer books (29.5\%). Bending or over reaching and frequent use of black board for teaching purpose (21.4\%) were also reported as perceived risk factors (Table 5).

Commonly adopted, self-reported coping strategies to overcome the musculoskeletal symptoms are represented in (Table 6).

$44.6 \%$ of teachers were coming up with the musculoskeletal symptoms by taking Physiotherapy treatment while 33.3\% were taking analgesics. $30.3 \%$ have been modifying their work pattern as a coping strategy to overcome the musculoskeletal symptoms (Table 6).

Table 7 and 8 represents the model summary and classification table of logistic regression analysis respectively.

Table 9 represents the logistic regression analysis of selected variables.

Table 4. Interference of symptoms with work

\begin{tabular}{|c|c|}
\hline Work Activities & $\mathbf{n}(\mathbf{\%}),(\mathbf{n}=\mathbf{1 1 2})$ \\
\hline Overall & $80(71.4)$ \\
\hline Writing work & $16(14.3)$ \\
\hline Standing long & $59(52.7)$ \\
\hline Sitting long & $21(18.8)$ \\
\hline Paper Checking & $27(24.1)$ \\
\hline Holding books & $3(2.7)$ \\
\hline
\end{tabular}

Table 5. Self perceived risk factors for musculoskeletal symptoms reported by participants

\begin{tabular}{|l|c|}
\hline Risk Factors & n (\%), (n=112) \\
\hline Standing Long & $86(76.8)$ \\
\hline Sitting Long & $14(12.5)$ \\
\hline Working on Computers & $8(7.1)$ \\
\hline Carrying heavy books & $23(20.5)$ \\
\hline Black board use & $24(21.4)$ \\
\hline Checking answer papers & $33(29.5)$ \\
\hline Bending/Over reaching & $24(21.4)$ \\
\hline Stair climbing & $33(29.5)$ \\
\hline
\end{tabular}

Table 6. Commonly used coping strategies to combat musculoskeletal symptoms

\begin{tabular}{|l|c|}
\hline Coping Strategies & $\mathbf{n}(\mathbf{\%}),(\mathbf{n}=\mathbf{1 1 2})$ \\
\hline Analgesics & $37(33.3)$ \\
\hline Physiotherapy & $50(44.6)$ \\
\hline Yoga & $25(22.3)$ \\
\hline Naturopathy & $4(3.6)$ \\
\hline Ayurveda & $8(7.1)$ \\
\hline Homeopathy & $14(12.5)$ \\
\hline Modifications of working pattern & $34(30.3)$ \\
\hline Use of support devices & $16(14.2)$ \\
\hline
\end{tabular}

Table 7. Model Summary of Logistic regression analysis

\begin{tabular}{|l|c|c|c|}
\hline Step & $\begin{array}{c}-2 \text { Log } \\
\text { likelihood }\end{array}$ & $\begin{array}{c}\text { Cox \& Snell R } \\
\text { Square }\end{array}$ & $\begin{array}{c}\text { Nagelkerke R } \\
\text { Square }\end{array}$ \\
\hline 1 & $472.773^{\mathrm{a}}$ & .134 & .209 \\
\hline
\end{tabular}

a. Estimation terminated at iteration number 20 because maximum iterations have been reached. Final solution cannot be found.

Table 8. Classification table of Logistic regression analysis

\begin{tabular}{|c|c|c|c|c|c|}
\hline \multicolumn{2}{|c|}{ Observed } & & \multicolumn{3}{c|}{ Predicted } \\
\cline { 3 - 4 } \multicolumn{2}{|c|}{} & \multicolumn{2}{|c|}{ MS symptoms } & Percentage & \\
\cline { 3 - 4 } \multicolumn{2}{|c|}{} & Yes & No & Correct & \\
\hline \multirow{3}{*}{ Step 1 } & MS & Yes & 14 & 98 & 12.5 \\
& symptoms & No & 9 & 416 & 97.9 \\
\cline { 3 - 4 } & & Overall & & & 80.1 \\
& & Percentage & & & \\
\hline
\end{tabular}

a. The cut value is .500

Table 9. Logistic regression analysis of variables in equation

\begin{tabular}{|l|l|l|l|l|l|l|l|}
\hline & B & Wald & Df & Sig. & $\begin{array}{l}\text { Exp } \\
\text { (B) }\end{array}$ & \multicolumn{2}{|l|}{$\begin{array}{l}\text { 95\% CI for } \\
\text { Exp (B) }\end{array}$} \\
\cline { 5 - 9 } & & & & & & & \\
\hline Age & -.037 & 3.068 & 1 & 0.080 & 0.964 & 0.925 & 1.004 \\
\hline Gender (1) & 1.374 & 10.113 & 1 & 0.001 & 3.952 & 1.694 & 9.217 \\
\hline Experience & & 3.746 & 3 & 0.290 & & & \\
\hline Experience (1) & 0.924 & 1.960 & 1 & 0.162 & 2.519 & 0.691 & 9.180 \\
\hline Experience (2) & 0.226 & 0.339 & 1 & 0.560 & 1.254 & 0.585 & 2.685 \\
\hline Experience (3) & 0.530 & 2.481 & 1 & 0.115 & 1.699 & 0.878 & 3.286 \\
\hline School Timing & & 0.620 & 2 & 0.733 & & & \\
\hline School Timing (1) & 0.244 & 0.103 & 1 & 0.748 & 1.276 & 0.288 & 5.647 \\
\hline School Timing (2) & 0.477 & 0.361 & 1 & 0.548 & 1.611 & 0.340 & 7.635 \\
\hline Work Hours & & 1.429 & 3 & 0.699 & & & \\
\hline Work Hours (1) & -.746 & 0.590 & 1 & 0.442 & 0.474 & 0.071 & 3.183 \\
\hline Work Hours (2) & 0.281 & 0.311 & 1 & 0.577 & 1.325 & 0.493 & 3.564 \\
\hline Work Hours (3) & 0.209 & 0.245 & 1 & 0.621 & 1.232 & 0.539 & 2.814 \\
\hline Number of classes & & 4.752 & 2 & 0.093 & & & \\
\hline $\begin{array}{l}\text { Number of classes } \\
\text { (1) }\end{array}$ & 0.899 & 4.619 & 1 & 0.032 & 2.458 & 1.082 & 5.583 \\
\hline $\begin{array}{l}\text { Number of classes } \\
\text { (2) }\end{array}$ & 0.333 & 0.426 & 1 & 0.514 & 1.395 & 0.514 & 3.787 \\
\hline
\end{tabular}


Risk factor analysis using logistic regression model on the cause of musculoskeletal pain showed statistical significance $\left(\chi^{2}(27)=77.169, \mathrm{p}<0.005\right)$. The model explained $20.9 \%$ (Nagelkerke $\mathrm{R}^{2}$ ) of the variance in musculoskeletal pain (Table 7) and correctly classified $80.1 \%$ of cases (Table 8 ). Females were 3.952 times more likely to exhibit musculoskeletal pain than males (OR 3.952, 95\% CI 1.694-9.217) (Table 9).

\section{Discussion and Conclusion}

The present study aimed to determine the prevalence of musculoskeletal symptoms, most affected anatomical sites of the body among school teachers and also focused on the commonly perceived risk factors that might contribute to these symptoms and most commonly adopted coping startagies to overcome the musculoskeletal symptoms.

Most literature reviewed by authors found very scanty literature available that focused on musculoskeletal symptoms as a whole, because low back, neck and shoulder pain were focused as primary areas of involvement in most of the studies. Higher prevalence rates of musculoskeletal pain in teachers were observed in studies conducted by Niluferkorkmaz et al., ${ }^{10}$ in Turkey, Chiu et al., ${ }^{11,12}$ in secondary school teachers in China (Only neck pain), Balakrishnan et al., ${ }^{13}$ among secondary school teachers in Pahang (Only low back pain) and Damayanti Sethy et al., ${ }^{14}$ in India (Only neck pain). However, the prevalence rate of our study was higher as compared to studies conducted in Japan ${ }^{15}$ and Malaysia ${ }^{16}$.

While neck, upper limb and back had been studied extensively, results from the present study indicating knee region involvement shows that lower limb needs to be considered as it can also be affected by work related musculoskeletal stress.

Despite the presence and severity of symptoms, only $17 \%$ of teachers have opted to take frequent sick leaves and this can be interpreted as teachers continuing their duties despite having musculoskeletal symptoms which might exaggerate them in long run.

Standing for long periods of time (76.8\%) was reported as the most common cause followed by stair climbing and evaluating answer books (29.5\%). This highlights the pattern of teaching followed commonly in our setup as teachers handle classes in standing for at least 40-45 minutes per period per day.

$44.6 \%$ of teachers reported taking Physiotherapy as a coping strategy to handle their pain. While this shows the awareness of physiotherapy options among teachers, it also highlights the attitude of society moving towards drug free aspect of health care. $30 \%$ of participants also tried to modify their working patterns and with appropriate ergonomic advice and supervision, this might help them not only to overcome their musculoskeletal pain but also to prevent recurrence of the symptoms and increase the productivity at work place.

Risk factor analysis using logistic regression model on the cause of musculoskeletal pain showed statistical significance $\left(\chi^{2}(27)=77.169, \mathrm{p}<0.005\right)$. The model explained $20.9 \%$ (Nagelkerke $\mathrm{R}^{2}$ ) of the variance in musculoskeletal pain and correctly classified $80.1 \%$ of cases. Females were 3.952 times more likely to exhibit musculoskeletal pain than males (OR 3.952, 95\% CI 1.694-9.217) and the number of classes taken per day by the teachers also influenced their musculoskeletal symptoms (OR 2.458, 95\% CI 1.082-5.583). No other factors were found to have a significant association with the musculoskeletal symptoms.

Unavailability of sufficient staff in most of the work setting like schools, leads to increased work load on available teachers. This might increase the load and in turn reduce the time required to recover from the load.

Based on the above discussion, it can be concluded that work patterns commonly used in schools needs to be revised based on the difficulties and musculoskeletal issues it can pose to teachers. Prevalence and risk factor perceptions of school teachers as reported in this study can be of significance in understanding and addressing these factors and appropriate measures to prevent and overcome them can be devised based on these results. Since the risk factors for musculoskeletal symptoms can be multifactorial in nature, the results of this present study need to be correlated with all possible mechanisms related to this population and further studies to determine the effectiveness of appropriate ergonomic modifications should be taken into consideration. This should also include involving the administrators as stake holders to understand the musculoskeletal problems of teachers and evaluating their severity on timely basis.

\section{References}

1. Mohan V, Justine M, Jagannathan M, Bt Aminudin S, Bt Johari SH. Preliminary study of the patterns and physical risk factors of work-related musculoskeletal disorders among academicians in a higher learning institute. J Orthop Sci. 2015; 20(2):410-7. https:// doi.org/10.1007/s00776-014-0682-4 PMid:25542222

2. Shuai J, Yue P, Li L, Liu F, Wang S. Assessing the effects of an educational program for the prevention of work-related musculoskeletal disorders among school teachers. BMC Public Health. 2014; 14:1211. https://doi.org/10.1186/1471-2458-14-1211 PMid:25422067 PMCid:PMC4256741

3. Yuichiro Ono TI, Shimaoka M, Hiruta S, Hattori Y, Ando S, Hori F, Tatsumi A. Associations of length of employment and working conditions with neck, shoulder and arm pain among nursery school teachers. Industrial Health. 2002; 40(2):149-58. https:// doi.org/10.2486/indhealth.40.149 PMid:12064556 
4. Yue P, Liu F, Li L. Neck/shoulder pain and low back pain among school teachers in China, prevalence and risk factors. BMC Public Health. 2012;12:789. https://doi.org/10.1186/1471-245812-789 PMid:22978655 PMCid:PMC3524038

5. Erick PN, Smith DR. Low back pain among school teachers in Botswana, prevalence and risk factors. BMC Musculoskelet Disord. 2014; 15:359. https://doi.org/10.1186/1471-2474-15-359 PMid:25358427 PMCid:PMC4230345

6. Rottermund AKJ, Saulicz E, Myśliwiec A, Saulicz M, Rygiel KA, Linek P. Back and neck pain among school teachers in Poland and its correlations with physical activity. Medycyna Pracy. 2015; 66(6):771-8. https://doi.org/10.13075/mp.5893.00121 PMid:26674164

7. Kovess-Masfety V, Sevilla-Dedieu C, Rios-Seidel C, Nerriere E, Chan Chee C. Do teachers have more health problems? Results from a French cross-sectional survey. BMC Public Health. 2006; 6:101. https://doi.org/10.1186/1471-2458-6-101 PMid:16630336 PMCid:PMC1523205

8. Cheng HK, Wong MT, Yu YC, Ju YY. Work-related musculoskeletal disorders and ergonomic risk factors in special education teachers and teacher's aides. BMC Public Health. 2016; 16:137. https://doi.org/10.1186/s12889-016-2777-7 PMid:26864071 PMCid:PMC4750223

9. Erick PN, Smith DR. A systematic review of musculoskeletal disorders among school teachers. BMC Musculoskelet Disord. 2011; 12:260. https://doi.org/10.1186/1471-2474-12-260 PMid:22087739 PMCid:PMC3250950
10. Korkmaz UCNC, Telci EA. Musculoskeletal pain, associated risk factors and coping strategies in school teachers. Scientific Research and Essays. 2011; 6(3):649-57.

11. Chiu TT, Lam PK. The prevalence of and risk factors for neck pain and upper limb pain among secondary school teachers in Hong Kong. Journal of Occupational Rehabilitation. 2007; 17(1):19-32. https://doi.org/10.1007/s10926-006-9046-z PMid:16933144

12. Chiu TW, Lau KT, Ho CW, Ma MC, Yeung TF, Cheung PM. A study on the prevalence of and risk factors for neck pain in secondary school teachers. Public Health. 2006; 120(6):563-5. https://doi.org/10.1016/j.puhe.2006.01.007 PMid:16684548

13. Rajan Balakrishnan MEC, Thenmozhi. Prevalence of low back pain and its risk factors among secondary school teachers at Bentong, Pahang. International Journal of Physical Education, Sports and Health. 2016; 3(2):35-40.

14. Sethy Damayanti MZ, Bajpai P. Occurrence of work related musculoskeletal disorders among school teachers in eastern and northeastern part of India. International Journal of Musculoskeletal Pain prevention. 2017; 2(1):187-92.

15. Tsuboi H, Takeuchi K, Watanabe M, Hori R, Kobayashi F. Psychosocial factors related to low back pain among school personnel in Nagoya, Japan. Industrial Health. 2002; 40(3):266-71. https://doi.org/10.2486/indhealth.40.266 PMid:12141375

16. Nurul Izzah Abdul Samad HA, Moin S, Mohd Tamrin SB, Hashim Z. Prevalence of low back pain and its risk factors among school teachers. American Journal of Applied Sciences. 2010; 7(5):6349. https://doi.org/10.3844/ajassp.2010.634.639 